\title{
ANALYSis OF Wind Velocity DATa in THE AREA OF THE City of SARAJeVo in Period From 1980-1990
}

\author{
Halima Hadziahmetovic, Ismira Ahmovic \& Rejhana Blazevic
}
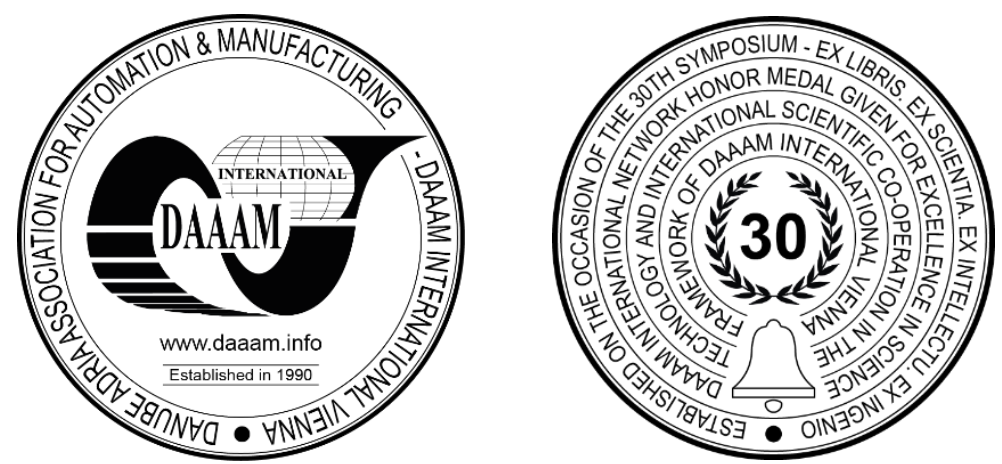

This Publication has to be referred as: Hadziahmetovic, H[alima]; Ahmovic, I[smira] \& Blazevic, R[ejhana] (2019). Analysis of Wind Velocity Data in the Area of the City of Sarajevo in Period from 1980-1990, Proceedings of the 30th DAAAM International Symposium, pp.0240-0247, B. Katalinic (Ed.), Published by DAAAM International, ISBN 9783-902734-22-8, ISSN 1726-9679, Vienna, Austria DOI: $10.2507 / 30$ th.daaam.proceedings.031

\begin{abstract}
In this paper analysis wind velocity data in the area of the city of Sarajevo in period 1980 to 1990. Data obtained from the Federal Hydrometeorological Institute of Bosnia and Herzegovina. After analysis wind velocity data in the area of the city of Sarajevo in period 1980 to 1990 are compared with the results obtained from the analysis of wind velocity data in the area of the city of Sarajevo in period 2000 to 2010. After that analysis, given more precise assessment of wind energy potential in the area of the city of Sarajevo.
\end{abstract}

Keywords: wind energy potential; meteorological station; average wind velocity; maximum win velocity; wind rose.

\section{Introduction}

The energy sector in Bosnia and Herzegovina has a long tradition and enormous potential for further development and investment. The total installed capacity of production facilities in Bosnia and Herzegovina is 4.352 MW, of which in larger hydropower plants it amounts to $2.083,50 \mathrm{MW}$, and in thermal power plants $2.065 \mathrm{MW}$. The installed capacity of small hydropower plants, wind, solar and biomass power plants is 112,15 MW [1].

Bosnia and Herzegovina is largely energy independent, as coal accounts for $65 \%$ of its total primary energy consumption. Over $90 \%$ of the produced coal is used for the production of electricity in thermal power plants. Second place is the production of electricity from hydroelectric power plants. Bosnia and Herzegovina has a large hydropotential estimated at $6.000 \mathrm{MW}$, of which only $35 \%$ of the available potential has been used [3].

Lately, for Bosnia and Herzegovina has expressed a great interest of investors for the production of electricity from renewable sources, in the first place from wind farms. It is estimated that the total potential of wind turbines is about 900 MW. The total technical potential is estimated at around 2.000 MW. The first wind farm in the territory of Bosnia and Herzegovina started its work on 14.03.2018. The wind farm Mesihovina is located in the central part of the Municipality of Tomislavgrad, has 22 wind turbines with a total installed capacity of 50,6 MW and an expected annual output of about 165.170 MWh [1], [2]. 
Bosnia and Herzegovina has the potential to use solar energy, which is estimated at around 70.500 million MWh of the total energy of total solar radiation annually. Currently, there are about 150 small solar power plants in Bosnia and Herzegovina, but their share in total electricity production is still negligible [1].

Therefore, the potentials for the use of energy from the renewable energy sources in Bosnia and Herzegovina are significant, and overcoming legal, technical and administrative barriers, as well as the establishment of encouraged measures, their use can become sustainable and environmentally acceptable. Achieving a compromise between the technically feasible, economically viable and environmentally acceptable would result in a faster development of electricity generation from the renewable energy sources.

\section{Wind potential in Bosnia and Herzegovina}

To assess the cost-effectiveness of a wind power generation plant, a very good knowledge of the wind characteristics in a particular area is needed. Therefore, before the construction of a wind farm, measurements of different atmospheric properties are carried out in order to better assess the wind potential at the given location. The same measurements must be carried out for a minimum of one year in order to obtain as little as possible deviation of the subsequent generation of electricity from the results obtained from the calculations based on the measurements [4]. It is estimated that $13 \%$ of the global land surface has a mean wind velocity greater than $6,9 \mathrm{~m} / \mathrm{s}$, which could theoretically produce 40 times more energy than the current total production [5].

DTU Wind Energy has developed the Global Wind Atlas in 2017, subsequent projects with the World Bank and international partners have supported further advancements. The Atlas is a free internet tool that would help investors identify areas with the most favorable wind power to build a wind farm. In Fig. 1., there is an atlas of wind, which shows the wind potential for the territory of Bosnia and Herzegovina [6].

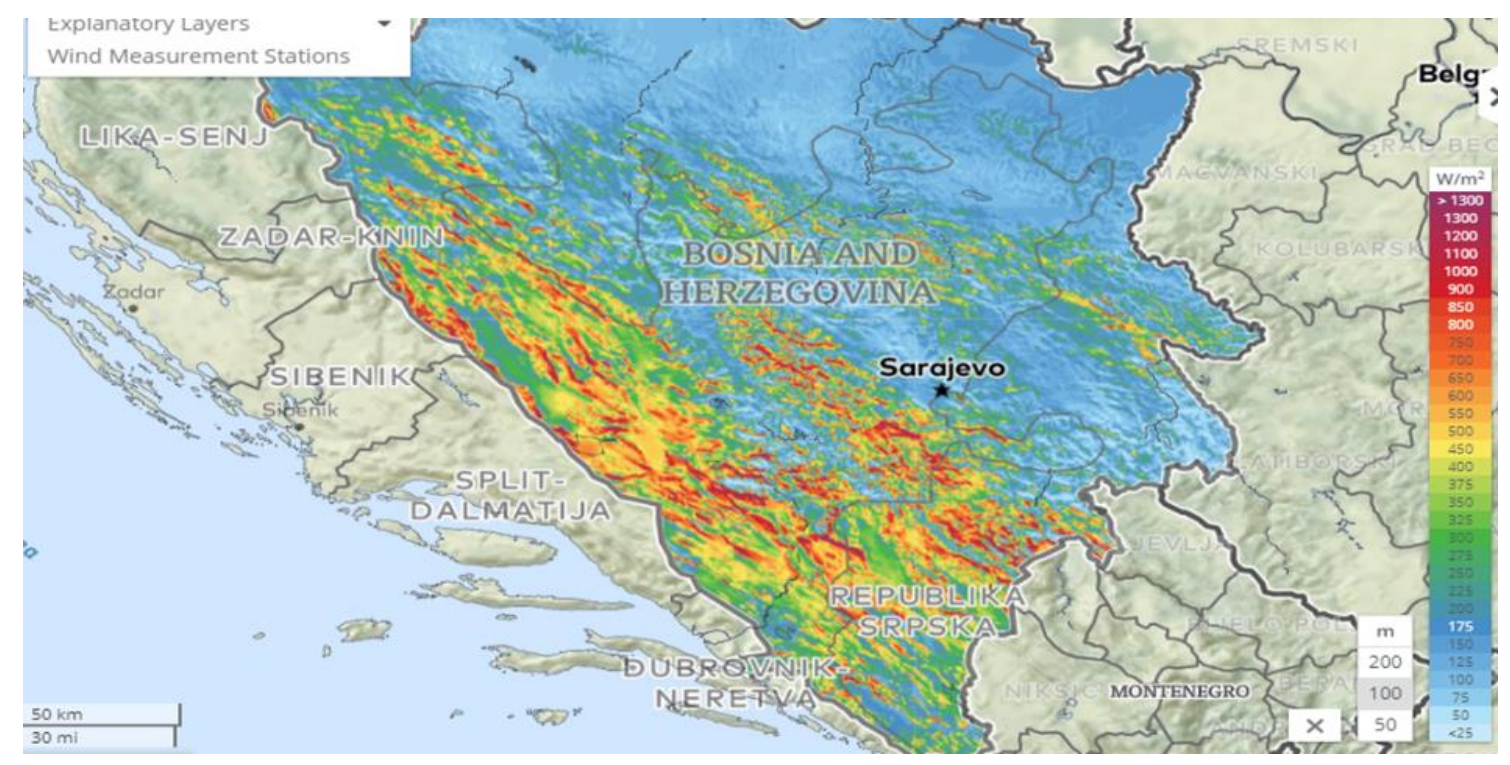

Fig. 1. Wind potential in the area Bosnia and Herzegovina [6]

From Fig. 1., it can be concluded that the maximum energy density is $1300 \mathrm{~W} / \mathrm{m}^{2}$. The reason for using the global wind atlas is that Bosnia and Herzegovina hasn't produced an atlas of wind, which would systematically describe the wind climatic features relevant for estimating the wind energy potential and planning the strategy of building wind farms at the state and entity levels. If the wind atlas would be available, along with other spatial substrates, such as topographic maps, satellite images, surface cover maps, etc., a credible technical assessment of wind energy in the Bosnia and Herzegovina area would be possible.

A major problem in the area of the city of Sarajevo (Canton of Sarajevo) is that during the winter period there is an increase in the concentration of harmful gases in the atmosphere (primarily $\mathrm{CO}_{2}$ ), as a result of the intensive use of fossil fuels. Constant growth of energy sources, then the increase in the price of electricity and the intensification of the effects of greenhouse gases is the main reason for the analysis of wind potential in the area of the Canton of Sarajevo. The paper analyzes and processes wind velocity data for the period from 1980 to 1990 for the area of Sarajevo (Bjelave), obtained from the Federal Hydrometeorological Institute of Bosnia and Herzegovina. The input data used for this analysis are: average monthly wind velocity, maximum monthly wind velocity and annual average wind velocity. After analysed data 
for the wind, a more accurate assessment of the wind potential for the period from 1980 to 1990 in the area of Sarajevo (Bjelave) was given guidelines for further research.

In paper [7] is analyzed data obtained from the Federal Hydrometeorological Institute of Bosnia and Herzegovina related to the wind velocity for the period from 2001 to 2010 in the area of the city of Sarajevo. Data obtained from the Federal Hydrometeorological Institute are the annual average wind velocity, average monthly wind velocity and maximum monthly wind velocity for the period from 2001 to 2010 . From this analysis of the wind velocity for the period from 2001 to 2010, it can be concluded that in the area of the city of Sarajevo there is a wind power potential, since the maximum wind velocity ranges from 8,3 to $25,9 \mathrm{~m} / \mathrm{s}$ but the average wind velocity range from 0 to $2,6 \mathrm{~m} / \mathrm{s}$. Because of the average wind velocity in the area of the city of Sarajevo (Bjelave), we decided to further explore the period from 1980 to 1990. This additional analysis should determine whether in the area of the city of Sarajevo has wind potential.

\section{Measurements of wind velocity in the meteorological station Sarajevo (Bjelave)}

This paper analyzes data obtained from the Federal Hydrometeorological Institute of Bosnia and Herzegovina related to the wind velocity in the area of the city of Sarajevo. Data obtained from the Federal Hydrometeorological Institute are the annual average wind velocity, average monthly wind velocity and maximum monthly wind velocity for the period from 1981 to 1990. Data for wind velocity and wind direction within meteorological station Sarajevo are obtained from a mechanical anemograph. Anemographs are instruments for registering wind direction and wind velocity. They consist of a sensory and registration part. The Fuess mechanical anemograph bar of Fig. 2. has a horizontal division for direction, average velocity and current wind velocity, and a horizontal (hourly) division for 10 . The direction division is at the top of the lane and is denoted by the letters $\mathrm{S}, \mathrm{E}$ and $\mathrm{N}$ for the upper feather and the letters $\mathrm{N}, \mathrm{W}$, and $\mathrm{S}$ for the lower [8].

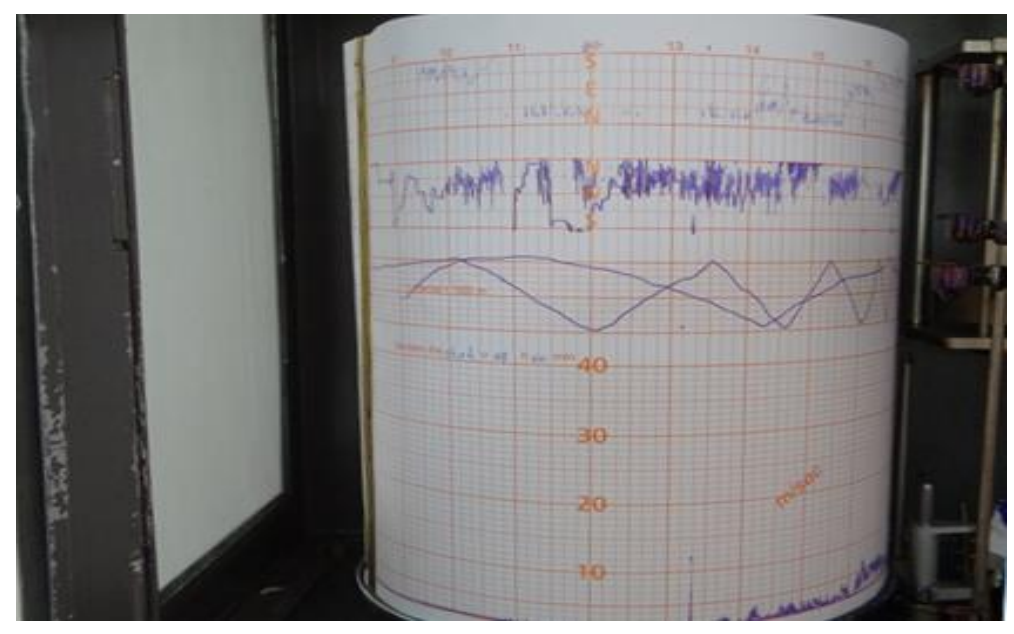

Fig. 2. Tape of Fuess mechanical anemograph from the Federal Hydrometeorological Institute in Bjelavama [8]

\section{Analysis of results}

The method used during the research is a linear regression method. The term linear regression refers to the method of modeling the dependence of the dependent stochastic variable on a set of independent variables in such a way that these dependences are linear. The simplest regression models use an independent meteorological variable. Basically, it is possible to construct regression models that use several meteorological variables. All regression coefficients of the forecasting model, depending on the type of regression method, are determined on the basis of statistical analysis of historical data on air movement [9].

The wind velocity at which the wind turbine is driven are about $3 \mathrm{~m} / \mathrm{s}$, with electricity production being rather small. The optimum wind velocity is about $12 \mathrm{~m} / \mathrm{s}$ (max. electricity production), and with the further increase in wind velocity, the amount of electricity does not increase even at velocities of 25 to $30 \mathrm{~m} / \mathrm{s}$, the wind turbine is switched off due to the high mechanical load [9].

Fig. 3. shows the results of the maximum and average wind velocity for the month of January in the period from 19801990 in the area of the city of Sarajevo. 


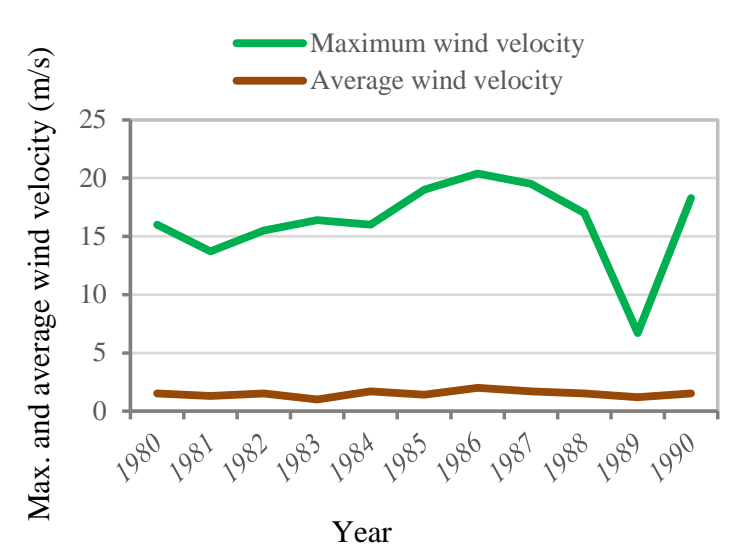

Fig. 3. Average and maximum wind velocity for the month of January in the period from 1980 to 1990 [8]

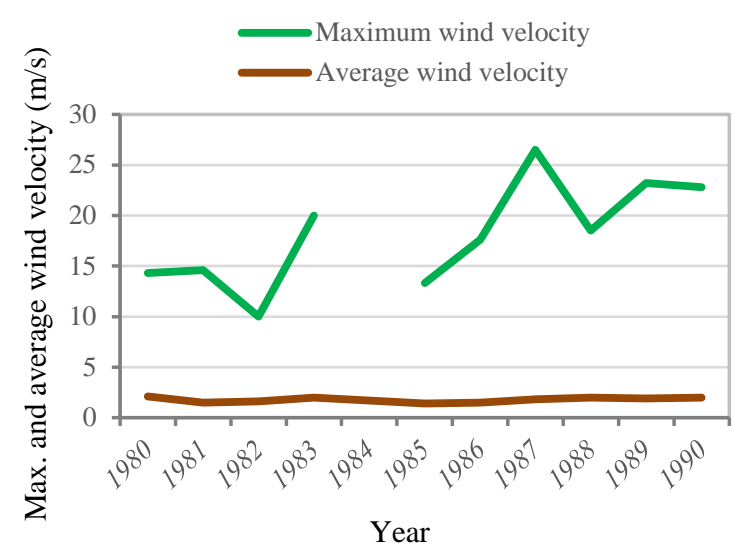

Fig. 4. Average and maximum wind velocity for the month of February in the period from 1980 to 1990 [8]

From Fig. 3., the lowest average wind was $1 \mathrm{~m} / \mathrm{s}$ in January 1983, while the highest average wind velocity was $2 \mathrm{~m} / \mathrm{s}$ in January 1986. The lowest maximum wind velocity was $6,7 \mathrm{~m} / \mathrm{s}$ in January 1989 , while the highest maximum wind velocity was $20,4 \mathrm{~m} / \mathrm{s}$ in January 1986 for the period from 1980 to 1990 . For period 2000 to 2010, the lowest average wind velocity was $0 \mathrm{~m} / \mathrm{s}$ in January 2008, while the highest average wind velocity was $2 \mathrm{~m} / \mathrm{s}$ in January 2001. The lowest maximum wind velocity was $7 \mathrm{~m} / \mathrm{s}$ in January 2009, while the highest maximum wind velocity was 20,4 m/s in January 2001. Based on the analysis of the results, it was concluded that there is not enough wind velocity for continuous operation, but according to the analysis of the maximum wind velocity there are high values, which are sufficient for the operation of the wind turbine. Fig. 4. shows the results of the maximum and average wind velocity for the month of February in the period from 1980-1990 in the area of the city of Sarajevo.

From Fig. 4., it can be concluded that the average wind velocity was range from 1,4 to $2,1 \mathrm{~m} / \mathrm{s}$ for the month of February in the period from 1980 to 1990, while for the month of February in the period from 2000 to 2010, the average wind velocity was in the range 0,1 to $2 \mathrm{~m} / \mathrm{s}$, which is not enough for continuous operation of the wind turbine. According to the analysis of the maximum wind velocity for the period 1980 to 1990 was range from 0 to $26,5 \mathrm{~m} / \mathrm{s}$, while for the month of February in the period from 2000 to 2010, the maximum wind velocity was range from 12,9 to $18,3 \mathrm{~m} / \mathrm{s}$, which is sufficient for the operation of the wind turbine. In February 1984, no measurements were made in the location due to a fault at the measuring station Sarajevo. Fig. 5. shows the results of the maximum and average wind velocity for the month of March in the period from 1980-1990 in the area of the city of Sarajevo.

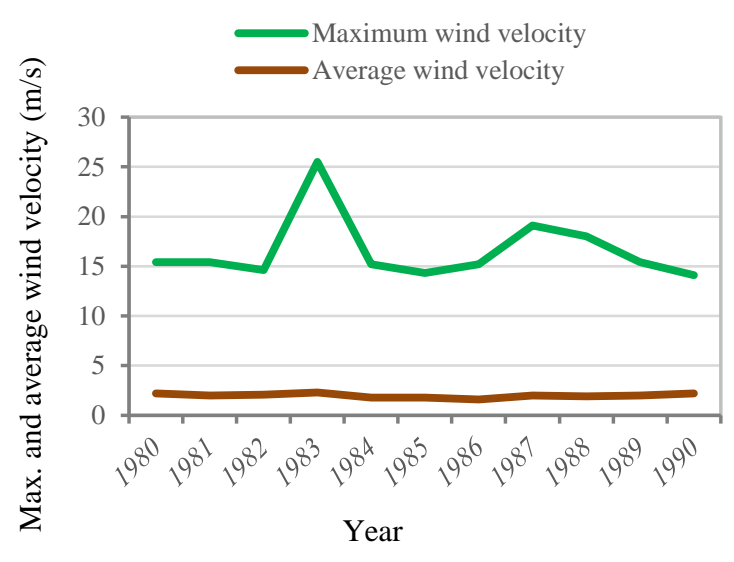

Fig. 5. Average and maximum wind velocity for the month of March in the period from 1980 to 1990 [8]

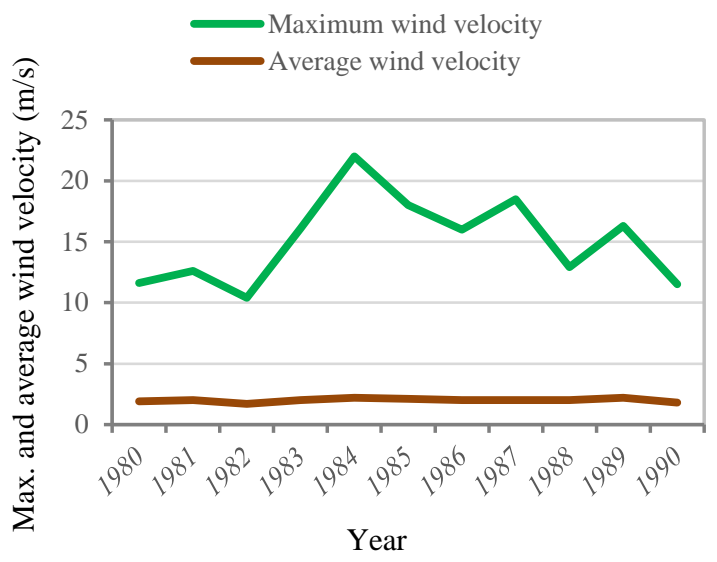

Fig. 6. Average and maximum wind velocity for the month of April in the period 1980 to 1990 [8]

From Fig. 5., the lowest average wind was 1,6 m/s in March 1986, while the highest average wind velocity was 2,3 $\mathrm{m} / \mathrm{s}$ in March 1983. The lowest maximum wind velocity was 14,1 m/s in March 1990, while the highest maximum wind velocity was 25,5 m/s in March 1983 for the period 1980 to 1990. For period 2000 to 2010, the lowest average wind velocity was $0,5 \mathrm{~m} / \mathrm{s}$ in March 2009, while the highest average wind velocity was 2,4 m/s in March 2001 and 2002 . The lowest maximum wind velocity was 13,2 m/s in March 2005, while the highest maximum wind velocity was $24 \mathrm{~m} / \mathrm{s}$ in March 2001. Based on the analysis of the results, it was concluded that there is not enough wind velocity for continuous 
operation, but according to the analysis of the maximum wind velocity there are high values, which are sufficient for the operation of the wind turbine. Fig. 6. shows the results of the maximum and average wind velocity for the month of April in the period from 1980 to1990.

From Fig. 6., it can be concluded that the average wind velocity was range from 1,7 to 2,2 m/s for the month of April in the period from 1980 to 1990, while for the month of April in the period from 2000 to 2010, the average wind velocity was in the range 0,2 to $2,4 \mathrm{~m} / \mathrm{s}$, which is not enough for continuous operation of the wind turbine.

According to the analysis of the maximum wind velocity for the period 1980 to 1990 was range from 10,4 to $22 \mathrm{~m} / \mathrm{s}$, while for the month of April in the period from 2000 to 2010, the maximum wind velocity was range from 11,7 to 19,6 $\mathrm{m} / \mathrm{s}$, which is sufficient for the operation of the wind turbine. Fig. 7. shows the results of the maximum and average wind velocity for the month of May in the period from 1980-1990 in the area of the city of Sarajevo.

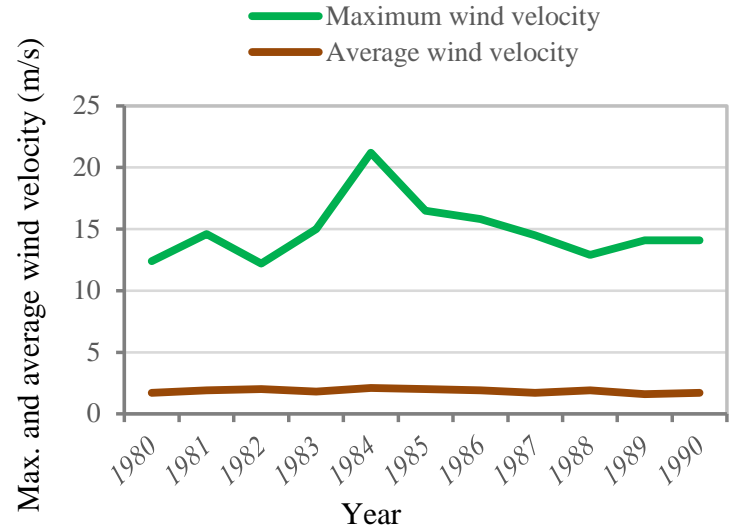

Fig. 7. Average and maximum wind velocity for the month of May in the period from 1980 to 1990 [8]

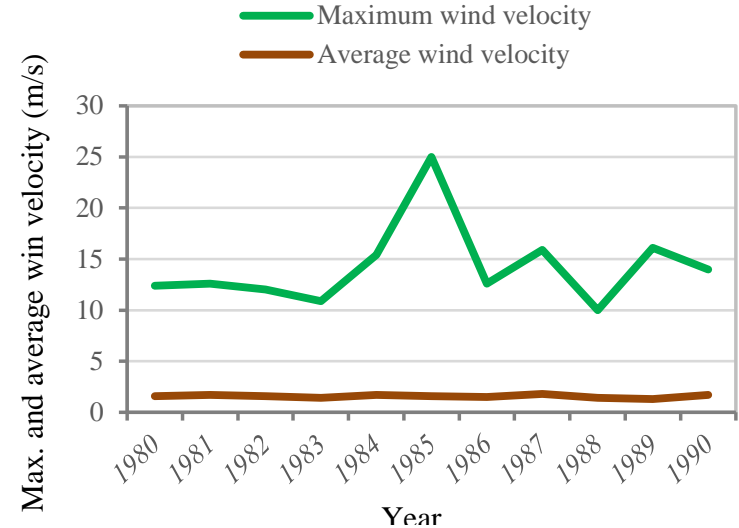

Fig. 8. Average and maximum wind velocity for the month of June in the period from 1980 to 1990 [8]

From Fig. 7., it can be concluded that the average wind velocity was range from 1,6 to $2,1 \mathrm{~m} / \mathrm{s}$ for the month of May in the period from 1980 to 1990, while for the month of May in the period from 2000 to 2010, the average wind velocity was in the range 0,1 to $2 \mathrm{~m} / \mathrm{s}$, which is not enough for continuous operation of the wind turbine. According to the analysis of the maximum wind velocity for the period 1980 to 1990 was range from 12,2 to 21,2 m/s, while for the month of May in the period from 2000 to 2010 , the maximum wind velocity was range from 8,7 to $22,5 \mathrm{~m} / \mathrm{s}$, which is sufficient for the operation of the wind turbine. Fig. 8. shows the results of the maximum and average wind velocity for the month of June in the period from 1980 to1990.

From Fig. 8., the lowest average wind was $1,3 \mathrm{~m} / \mathrm{s}$ in June 1989, while the highest average wind velocity was $1,8 \mathrm{~m} / \mathrm{s}$ in June 1987 for the period from 1980 to 1990. The lowest maximum wind velocity was $10 \mathrm{~m} / \mathrm{s}$ in June 1988, while the highest maximum wind velocity was $25 \mathrm{~m} / \mathrm{s}$ in June 1985. While for the month of June in the period from 2000 to 2010 , the maximum wind velocity was in the range 11,5 to $20,2 \mathrm{~m} / \mathrm{s}$ and the average wind velocity was range from 0 to $2,2 \mathrm{~m} / \mathrm{s}$. In June 2009, no measurement were made in the location due to a fault at the measuring station Sarajevo. Fig. 9. shows the results of the maximum and average wind velocity for the month of July in the period from 1980-1990 in the area of the city of Sarajevo.

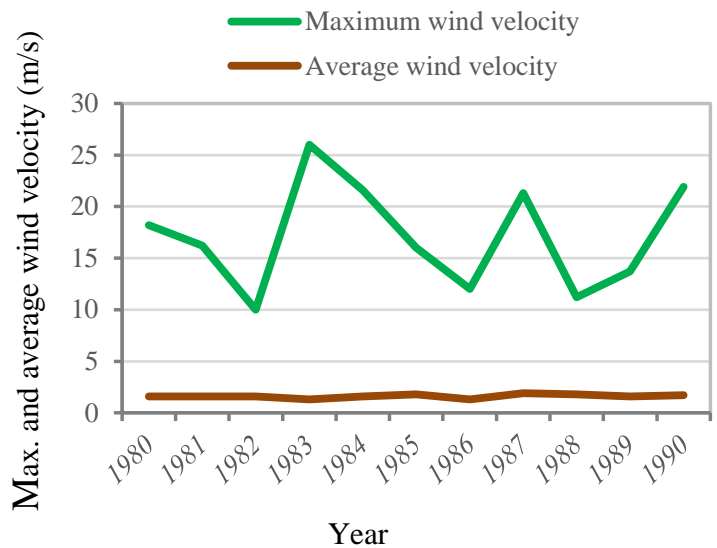

Fig. 9. Average and maximum wind velocity for the month of July in the period from 1980 to 1990 [8]

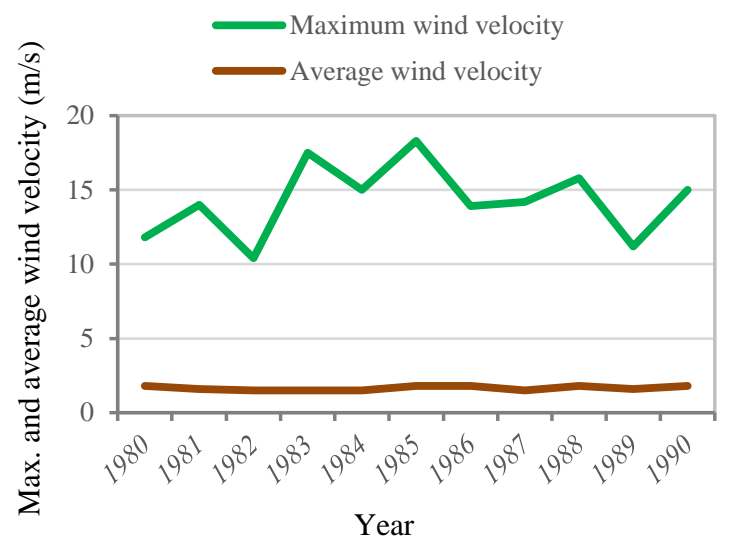

Fig. 10. Average and maximum wind velocity for the month of August in the period from 1980 to 1990 [8] 
From Fig. 9., the lowest average wind was 1,3 m/s in July 1983 and 1986, while the highest average wind velocity was $1,9 \mathrm{~m} / \mathrm{s}$ in July 1987 . The lowest maximum wind velocity was $10 \mathrm{~m} / \mathrm{s}$ in July 1982, while the highest maximum wind velocity was $26 \mathrm{~m} / \mathrm{s}$ in July 1983 for the period from 1980 to 1990. For period 2000 to 2010, the lowest average wind velocity for July was 1,6 m/s in July 2002, while the highest average wind velocity was 2,1 m/s in July 2000 and 2007. The lowest maximum wind velocity was $10,4 \mathrm{~m} / \mathrm{s}$ in July 2008 , while the highest maximum wind velocity was $20,4 \mathrm{~m} / \mathrm{s}$ in July 2004. Based on the analysis of the results, it was concluded that there is not enough wind velocity for continuous operation, but according to the analysis of the maximum wind velocity there are high values, which are sufficient for the operation of the wind turbine. Fig. 10. shows the results of the maximum and average wind velocity for the month of August in the period from 1980 to 1990.

From Fig. 10., the lowest average wind was 1,5 m/s in August 1982, 1983, 1984 and 1987, while the highest average wind velocity was $1,8 \mathrm{~m} / \mathrm{s}$ in August 1980, 1985, 1986 and 1990. The lowest maximum wind velocity was 10,4 m/s in August 1982, while the highest maximum wind velocity was 18,3 m/s in August 1985. The lowest average wind for August was 1,6 m/s in August 2002, 2005, 2006 and 2009, while the highest average wind velocity was 2,2 m/s in August 2010. The lowest maximum wind velocity was $11,8 \mathrm{~m} / \mathrm{s}$ in August 2010, while the highest maximum wind velocity was $18,9 \mathrm{~m} / \mathrm{s}$ in August 2004 for the period from 2000 to 2010. Based on the analysis of the results, it was concluded that there is not enough wind velocity for continuous operation, but according to the analysis of the maximum wind velocity there are high values, which are sufficient for the operation of the wind turbine. Fig. 11. shows the results of the maximum and average wind velocity for the month of September in the period from 1980 to 1990.

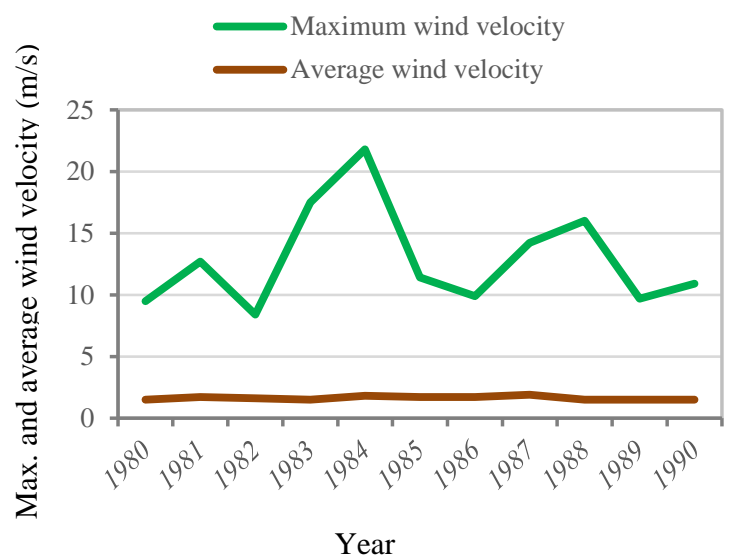

Fig. 11. Average and maximum wind velocity for the month of September in the period from 1980 to 1990

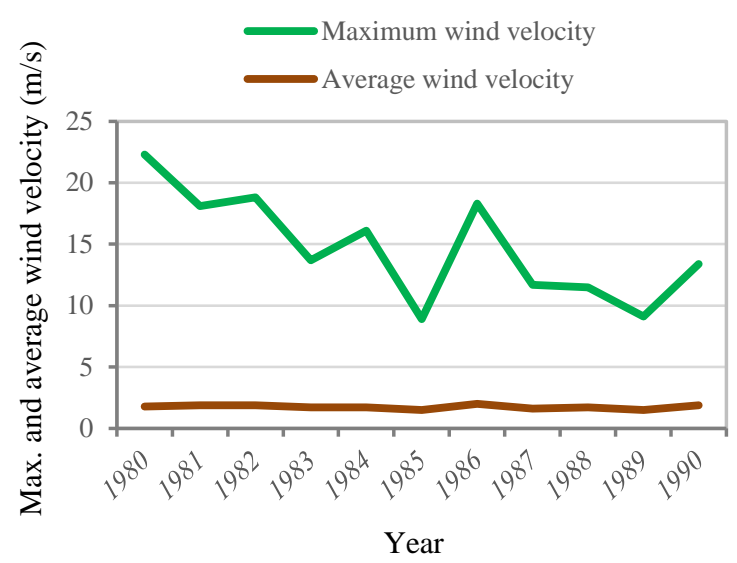

Fig. 12. Average and maximum wind velocity for the month of October in the period from 1980 to 1990 [8] [8]

From Fig. 11., the lowest average wind was 1,5 m/s in September 1980, 1983, 1988, 1989 and 1990, while the highest average wind velocity was $1,9 \mathrm{~m} / \mathrm{s}$ in September 1987 . The lowest maximum wind velocity was $8,4 \mathrm{~m} / \mathrm{s}$ in September 1982, while the highest maximum wind velocity was $21,8 \mathrm{~m} / \mathrm{s}$ in September 1984 . For the month of September in the period from 2000 to 2010 , the maximum wind velocity was in the range 8,3 to $18,9 \mathrm{~m} / \mathrm{s}$ and the average wind velocity was in the range 0 to $1,9 \mathrm{~m} / \mathrm{s}$. No measurement were made in September 2009 due to a malfunction at the measuring station Sarajevo. Based on the analysis of the results, it was concluded that there is not enough wind velocity for continuous operation, but according to the analysis of the maximum wind velocity there are high values, which are sufficient for the operation of the wind turbine. Fig. 12. shows the results of the maximum and average wind velocity for the month of October in the period from 1980 to 1990.

From Fig. 12., the lowest average wind was 1,5 m/s in October 1985 and 1989, while the highest average wind velocity was $2 \mathrm{~m} / \mathrm{s}$ in October 1986. The lowest maximum wind velocity was 8,9 m/s in October 1985, while the highest maximum wind velocity was $22,3 \mathrm{~m} / \mathrm{s}$ in October 1980 . The lowest average wind for October was $1,5 \mathrm{~m} / \mathrm{s}$ in October 2007 and 2009, while the highest average wind velocity was $2 \mathrm{~m} / \mathrm{s}$ in October 2000 and 2002. The lowest maximum wind velocity was $9 \mathrm{~m} / \mathrm{s}$ in October 2005, while the highest maximum wind velocity was $22 \mathrm{~m} / \mathrm{s}$ in October 2003 for the period 2000 to 2010. Based on the analysis of the results, it was concluded that there is not enough wind velocity for continuous operation, but according to the analysis of the maximum wind velocity there are high values, which are sufficient for the operation of the wind turbine. Fig. 13. shows the results of the maximum and average wind velocity for the month of November in the period from 1980 to 1990. 


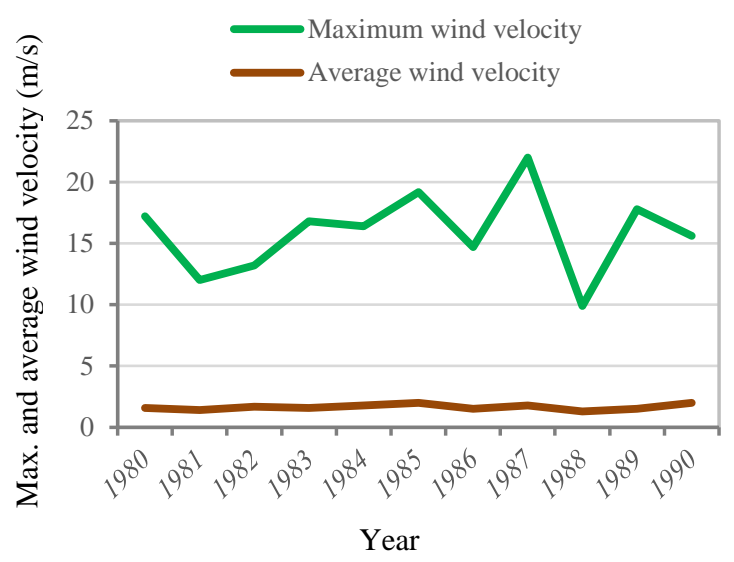

Fig. 13. Average and maximum wind velocity for the month of November in the period from 1980 to $1990[8]$

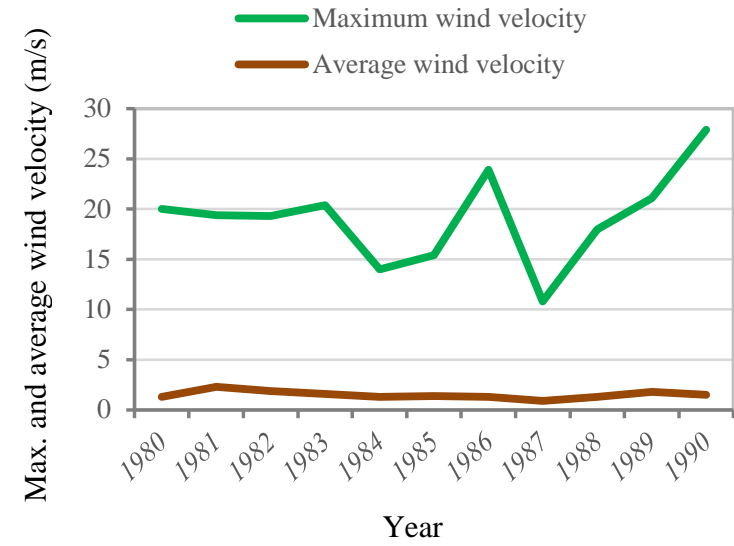

Fig. 14. Average and maximum wind velocity for the month of December in the period from 1980 to 1990

[8]

From Fig. 13., the lowest average wind was $1,3 \mathrm{~m} / \mathrm{s}$ in November 1988 , while the highest average wind velocity was $2 \mathrm{~m} / \mathrm{s}$ in November 1985 and 1990. The lowest maximum wind velocity was 9,9 m/s in November 1988, while the highest maximum wind velocity was $22 \mathrm{~m} / \mathrm{s}$ in November 1987. While for the month of November the period 2000 to 2010 , the average wind velocity was in the range 1,4 to $2,3 \mathrm{~m} / \mathrm{s}$ and maximum wind velocity was in the range 10,5 to $25,9 \mathrm{~m} / \mathrm{s}$. Based on the analysis of the results, it was concluded that there is not enough wind velocity for continuous operation, but according to the analysis of the maximum wind velocity there are high values, which are sufficient for the operation of the wind turbine. Fig. 14. shows the results of the maximum and average wind velocity for the month of December in the period from 1980 to 1990. From Fig. 14., the lowest average wind was 0,9 m/s in December 1987, while the highest average wind velocity was $2,3 \mathrm{~m} / \mathrm{s}$ in December 1981 . The lowest maximum wind velocity was $10,8 \mathrm{~m} / \mathrm{s}$ in December 1987, while the highest maximum wind velocity was $27,9 \mathrm{~m} / \mathrm{s}$ in December 1990 . While for the month of December the period 2000 to 2010, the average wind velocity was in the range 1,4 to 2,6 m/s and maximum wind velocity was in the range 13 to $21,9 \mathrm{~m} / \mathrm{s}$. Based on the analysis of the results, it was concluded that there is not enough wind velocity for continuous operation, but according to the analysis of the maximum wind velocity there are high values, which are sufficient for the operation of the wind turbine.

\section{Wind rose}

The wind rose is a graphic representation of the average strength and wind velocity from certain directions. Fig. 15. shows the wind rose for measuring station Sarajevo from 1980 to 1990. The wind rose for measuring station Sarajevo from 1980 to 1990 is at the same as the wind rose for measuring station Sarajevo from 2001 to 2010, from which it can be concluded that no significant changes have occurred. The winds in the Sarajevo basin are directly determined by the effects of regional atmospheric circulation and relief terrain. Under their influence, two basic types of wind are formed: with a daily period and occasional. The main local winds are the danik (valley wind) and noćnik (mountain wind). The prevailing wind blowing direction is E-W and is conditioned by the basin morphology of the terrain [8].

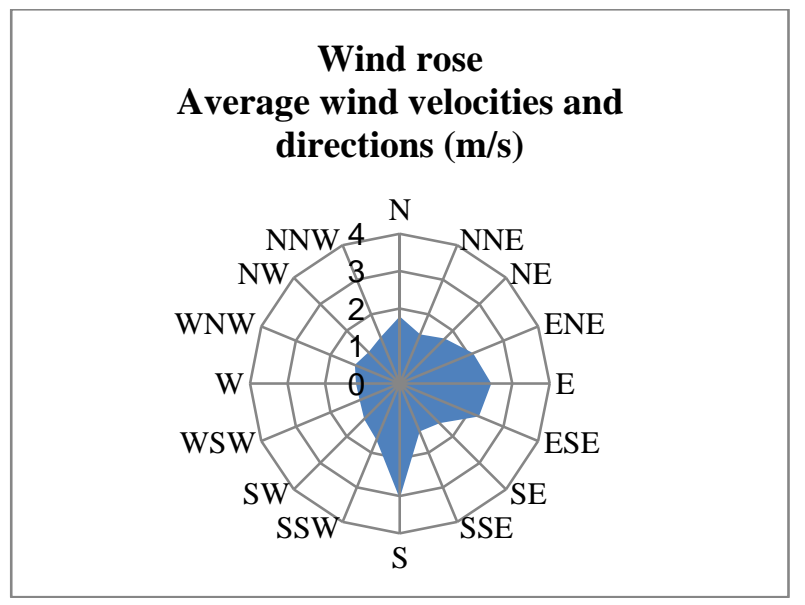

Fig. 15. Wind rose for measuring station Sarajevo from the period 1980 to 1990 [8] 


\section{Conclusion}

In this paper, they have been analysis data obtained from the Federal Hydrometeorological Institute are the average monthly wind velocity and the maximum monthly wind velocity in the area of the city of Sarajevo in period 1980 to 1990. The analysis used tens of thousands of data related to wind velocity in the area of the city of Sarajevo for the period mentioned.

From the analysis conducted earlier wind velocity in the area of the city of Sarajevo in period 2000 to 2010 , it can be concluded that the maximum wind velocity range to $25,9 \mathrm{~m} / \mathrm{s}$ and the average wind velocity range to $2,6 \mathrm{~m} / \mathrm{s}$.

From the analysis wind velocity in the area of the city of Sarajevo in period 1980 to 1990 , it can be concluded that the maximum wind velocity range to $27,9 \mathrm{~m} / \mathrm{s}$ and the average wind velocity range to $2,3 \mathrm{~m} / \mathrm{s}$.

Based on the analysis of the results, it was concluded that there is not enough wind velocity for continuous operation, but according to the analysis of the maximum wind velocity there are high values, which are sufficient for the operation of the wind turbine.

If the results obtained from the analysis of the average wind velocity in the area of the city of Sarajevo in period 1980 to 1990 are compared with the results obtained from the analysis of average wind velocity in the area of the city of Sarajevo in period 2000 to 2010, the average wind velocity for the period from 2000 to 2010 increased by $0,3 \mathrm{~m} / \mathrm{s}$.

For the results obtained from the analysis of the maximum wind velocity in the area of the city of Sarajevo in period 1980 to 1990 are compared with the results obtained from the analysis of maximum wind velocity in the area of the city of Sarajevo in period 2000 to 2010, the maximum wind velocity for the period from 1980 to 1990 increased by 2-3 m/s.

In order to confirm with certainty whether there is a wind energy potential in the area of the city of Sarajevo, an hourly wind velocity should be estimated for both analyzed periods. After that analysis, the number of hours the wind turbine would operate would be used to determine the power of the wind turbine.

\section{Acknowledgements}

This paper is realized in framework of project supported by the Federal Ministry of Education and Science.

\section{References}

[1] http://www.mvteo.gov.ba/content/read/energetika, (2018). Ministarstvo vanjske trgovine i ekonomskih odnosa Bosne i Hercegovine, Accessed on: 2019-09-09

[2] Zlomušica, E.; Čampara, M. \& Dedić, R. (2015). Vjetroelektrane - osnove konstrukcije i rada, Agromediteranski fakultet Univerziteta „Džemal Bijedić“, ISBN: 978-9958-604-90-4, Mostar, Bosna i Hercegovina.

[3] Begić, F. \& Hadžiabdić, M. (2011). Energija vjetra, Mašinski fakultet Sarajevo i Internacionalni univerzitet u Sarajevu, ISBN: 978-9958-896-07-1, Sarajevo, Bosna i Hercegovina.

[4] Spera, D. A. (2009). Wind Turbine Technology: Fundamental Concepts in Wind Turbine Engineering, American Society of Mechanical Engineers, ISBN: 9780791802601, New York, USA

[5] Gasch, R. \& Twele, J. (2012). Wind Power Plants- Fundamentals, Design, Construction and Operation Second Edition, Springer-Verlag Berlin Heidelberg, ISBN: 978-3642229374, Berlin, Germany

[6] https://globalwindatlas.info/en/, (2019). The World Bank and Technical University of Denmark, Accessed on: 2019-09-12

[7] Hadziahmetovic, H.; Dzaferovic E.; Ahmovic, I. \& Blazevic, R. (2018). Analysis of Wind Velocity Data in the Area of the City of Sarajevo in Period from 2001-2010, Proceedings of the 29th DAAAM International Symposium, Zadar, Croatia, ISSN 1726-9679, ISBN 978-3-902734-20-4, B. Katalinic (Ed.), pp.0250-0259, Published by DAAAM International, Vienna, Austria, DOI: 10.2507/29th.daaam.proceedings.036

[8] http://fhmzbih.gov.ba/latinica/ (2019). Federalni hidrometeorološki zavod Bosne i Hercegovine, Accessed on: 2019-03-09

[9] Manwell, J.F.; McGowan, J.G. \& Rogers, A.L. (2009). Wind Energy Explained: Theory, Design and Application Second Edition, John Wiley \& Sons, Ltd, ISBN:9780470015001, Chichester, UK. 